\title{
The Limits of Creativity and the Translator's Responsibility
}

\section{Niranjan Mohanty}

\begin{abstract}
Any attempt to discover or locate creativity in the translator or in translation is likely to cause ostensible debate or even to raise eyebrows. This is precisely because, as this paper tries to argue, of our notions of the translator as a shadowy presence or a negotiator or a compromise seeking agent between two languages and two cultures. Yet, in the act of translation, it is difficult to do away with the idea of the translator's presence in the absence of the SL Text author. The absence of the SL text's author brings in more responsibilities on the translator. Thus the translator's responsibilities are three-fold: firstly, to the SL text or SL text's Target Culture. Within this limited space of creativity and sphere of responsibility, a translator has to work. But his/her primary task would be two-fold: firstly to transplant the spirit or essence of the SL text in the TL text by de-familiarizing the Source Language; secondly to familiarize the SL emerge at this stage of translation. Familiarization of the SL: Culture to the TL culture and its audience depends much upon the political relation between the two countries. If politically the two countries are proactive, meaningfully interactive, then the process of familiarization of the SL culture to the TL culture would not pose any problem. But to be honest, the translator does not deliberately attempt at
\end{abstract}

Translation Today Vol. 2 No. 2 Oct. 2005 @ CIIL 2005 
familiarizing the SL culture to the TL culture. As the translator handles the languages along with the transfer of meaning into another language, certain aspects of culture automatically get transferred into the matrix of Target culture.

Debates on the nature of translation as a mechanical activity or a creative one, on the transfer of meaning from the SL text to the TL text, on the impossibility of identifying 'equivalence' (both in terms of signifiers and signifieds), on the 'literal' (i.e. word to word) or free translation on the role of the translator in familiarizing or defamiliarizing the Source Language, on the complexities and difficulties involved in translating culture specific items, and finally on the ways and means of deciphering the 'quality' of translation have enriching, and even at times, intriguing effects, both on the translators and experts on Translation Studies. This paper is an attempt to show the limits of the translator's creativity (with the basic assumption that translation is a creative activity, even if some argue that it is an adjunct to creativity), and more particularly, the translator's role, in finding out means, if any, to overcome the difficulties in transferring the culture specific-items of the SL text to the TL text and ultimately to the TL culture.

\section{The layer of intention:}

A literary translator's responsibility lies (after identification of the 'text' he/she is to translate) in identifying the layer of intention of the author of the SL text. And this layer cannot be perceived, unless the translator reads minutely, passionately, the whole text and not a part of it. The translator's 'intention' should be to reach, capture and represent the intention of the author of the SL text. All other 'intentions' of the translator should be kept low-keyed, should remain elusive. In order to reach the intention of the SL author, a translator has to be a judicious critic, or an intelligent interpreter. In 
trying to know this 'intention', the translator must use his/her critical insight to uncover the tone of voice, the metaphor, the allusions (if any), the similies, irony, paradoxes, shifts and turns and all such devices available in the corpus of the SL text. It is, therefore, not binding on the part of the translator to transplant all such literary devices into the TL text. He can reinvent new strategies, new devices as they are available or conveniently acceptable in the Target Language. His sole objective should be to decode, unmask, demystify, but not completely defamiliarise the literary devices to reach the layer of intention as posited in the SL text.

It is true that literary translation is neither to copy nor to mime the SL text. It is worth noting in this context what the Argentinean writer Jorge Louis Borges once told Gregory Rabassa, one of the most earnest translators: "Don't translate what I've written but what I wanted to say." The tone of voice reflects the author's attitude towards a particular object or person or experience or incident as presented or depicted in the text. This has to be retained in the TL text. Walter Benjamin considers the intended effect upon the language as the layer of intention. Benjamin writes:

The task of the translator consists in finding that intended effect (intention) upon the language into which he is translating which produces in it the echo of the original. This is a feature of translation which basically differentiates it from the poet's work, because the effort of the latter is never directed at the language as such, at its totality, but solely and immediately at linguistic contextual aspects.

Identification of such layer of intention and its representation, its reallocation in the TL text, despite variation in the use of literary devices, remain central to the translation process. 


\section{The layer of Objective Orientation:}

Bereft of an 'objective orientation' or the layer of objective orientation, a translator may not achieve the limited creativity in the TL text. A translator has to adhere to what Henrik Gottlieb terms as "source text typology and transfer typology". The translator can familiarize himself/herself with specific characteristic features of the SL text to be translated. These are factuality (falsifiable/real/non falsifiable text), function (informative/persuasive /emotive/logical/entertaining), provenance (mundane/divine), age of the text (recent/aged/or dated/classical), setting (familiar/exotic/magical/completely imaginary/fashionable), linguistic conventions (shared/ different), semiotic structure (monosemiotic or simple/poly-semiotic or complex), receptivity (actordefined/audience defined, writerly/readerly), identity of the author (known or familiar/unknown), audience (private/public). The translator has to know or identify the nature of transfer that he/she is to make in the TL text. Such variables include, i) purpose of translation, ii) direction of transfer (into native language or nonnative, native form or non-native), directness of transfer (direct/relay translation) preparation (planned/impromptu), balance between semiotic methods (language formal structures, syntactical orders retained/altered), status of the text in translation (translator credited/not credited), target audience (within a country/outside, including the cultures, children/adult, old; elite/merely literate), target language (dominant/repressed), target culture (east/west), publisher (private/celebrity). Recognizing such parameters can always lead to a certain degree of excellence in translation. Such an objective orientation makes the translator confident. Without such assurance or confidence, no translator can hope to achieve excellence, even if he/she is fully aware of the fact that in translation, everything of the SL text cannot be transferred, and that whatever he/she would transfer into the TL text would generate another text, a new text altogether in a new culture. I am at once reminded of what A.K. Ramanujan had to say in the "Afterword" of 
his poems of Love and war (from the eight Anthologies and ten Long poems of classical Tamil) in connection with his experience as a translator in particular and the role of the translator in general:

He has a double allegiance, indeed, several double allegiances. All too familiar with the rigors and pleasures of reading a text and those of making another, caught between the need to express himself and the need to represent another, moving between the two halves of a brain, he has to use both to get close to "the originals". He has to let poetry win without allowing scholarship to lose. Then his very compromises may begin to express certain fidelity and may suggest what he cannot convey. Crossing languages, one ancient or foreign, another current or familiar, searching in one language for forms and tones that will mimic and relieve those of another, he may fashion now and then a third that will look like the one speak like (or for) the other...In translating these poems, I have tried to attend always to the minute particulars of individual poems, the words, the syntax, and through them the world in the words.

This "double allegiance" of the translator does not distort or deform his singular intention of achieving proximity with the SL text-at least in essence, in spirit, in intended meaning of the SL text or of the SL author. And in achieving this proximity, the strategies he employs, the devices he chooses to make use of out of the available many in the target language, the translator's creative role is uninterrupted. What Giovanni Pontiero observed in assigning the role of a translator can bear some meaningful insight:

Literary translation, therefore, is no mean task. It is an art worthy of greater recognition from publishers, critics and readers. The job requires intelligence and experience, but also humility, courage, heart, and imagination. 
The translator's imagination or intention must not be restricted only to transfer meaning or to "convey information," but to intensify or represent the meaning as does a creative writer with a view to engendering certain creativity to his act of translation. Frances R Aparicio in her study of modern translations in the context of Latin-America maintains:

Translating implies interpreting, creating. It is an analogous process to that of creation and innate to the poetic view of reality. It is a way of seeing and reading our world. It is therefore has a function of a metaphor of meaning, and as such it represents for modern literary criticism the important process of reading as an alternative act of writing.

\section{Context of Culture}

Since the translator is engaged with languages and languages are pointers and guides to social reality, and are "steeped in the context of culture", any translation unknowingly transfers some aspects of the SL culture to the TL culture. Language is a repository of co-ordinates of culture and is a transmitter of such coordinates through then, is the heart within the body of culture, and it is the interaction between the two that results in the continuation of life energy.

In a paper "Translation: A symbiosis of cultures", I asserted, citing my translation of Salabega's (a $17^{\text {th }}$ century devotional poet of Orissa) prayer poems:

I believe that it is not the scope of the target language that is expanded but the scope of the deposits of source culture from which the translation originated that is enlarged. In other words in translation two activities happen simultaneously: one of defamiliarisation of the source language and one of familiarization of the source 
culture into the target culture. If the values, attitudes and relationships which constitute the source culture are reflected thoroughly in the source language, and the translation is executed with excellence and perfection, I am sure that the initial symbiosis of two cultures at the linguistic level would lead to the same process in the societal level.

I reiterate the same view because much depends on extra literary factors, so far as the relationship between two countries, two languages, two societies and two mind sets is concerned. Hierarchy in relation between two countries or two cultures would invariably affect the status of the translated text. A systematic study of Tagore's reception in the west reveals that his works in English rendering could hardly create any lasting impact on the western mind as his appreciators and detractors uniformly treated Tagore as a sage, -which he was, but more than that- failing to fathom Tagore's subtle human touches, his humility, his zest for life, his probing into human psyche, his celebration of life. I would like to quote here how the reviewer for The Manchester Guardian could only discover elements of mysticism in The Fugitive, and commented on Gitanjali as: "their message was remote, it was strange or unintelligible. We treasure the volume as we treasure a Persian carpet or a Japanese print." The reviewer, to my mind, was honest in the first sentence, but seems to champion an imperialist project or a sympathetic stance in the second. Indeed, what a colonial tribute to the only Nobel Laureate in literature from India! The reason behind citing this example is only to allude to two interesting facts:

i) The fate of a translated text in another culture which is governed by an imperialist attitude towards the literatures produced in that culture.

ii) The exoticist attitude to India 
In both these facts, as revealed by the reviewer, what is missing is the objective evaluation of Gitanjali, which, I believe no western critic can undertake. Is it because his mind-set is different and which fails to unearth the spirit of the poem, the greatness, the universal approach of the poem? Is it because of the absence of English-English in the translated Gitanjali?

Is it because Tagore's own translation failed to do justice to his work? Possibly it was because of both that Gitanjali's reception was adumbrated. Reception of a translated text in the target culture inescapably depends upon the power relations between the countries. Even if India is free today and translation of regional literatures has taken a sizeable space, what is lamented upon is the quality of translation. Salman Rushdie in The New Yorker article expresses his dissatisfaction over the non-availability of Indian texts in appreciably good translation. Rushdie observed:

Admittedly, I did my reading only in English, and there has long been a problem of translation in India -not only into English but between the vernacular languagesand it is possible that good writers have been ill served by their translators' inadequacies...

The lack of first-rate writing in translation can only be a matter of regret.

Thus even in the period when we are free, the reception of the translated text experiences no better situation. Should we then stop translation or translating our own regional literatures? The answer, to my mind, is categorically 'no' simply because, such translations initiate a symbiosis of cultural-relations, at least, within the country, between one region and another.

For the translator, culture remains always problematic. Every language offers resistance to translation, as it changes its 
colour under another sky. It is paradoxical that because of such a culture specific factor, translation becomes a necessity. In the initial stages of translation practices, foot-notes, translator's comments, were used plentifully with a view to bringing the TL text comprehensively closer to the SL text. Neither the translators nor the publishers appreciate today this way of handling a translated text.

The linguistic and pragmatic issues involved in the process of translation can be dealt with in consonance with the choices that the translator has to make and because of the perambulating habit of the translator in finding out the most persuasive choice. I posit creativity to the act of translation. It would be relevant to know what Giovanni Pontiero, as a celebrity translator had to say:

The study of the cultural background of the work to be translated is crucial and, the more important the writer (e.g. Umberto Eco, Jose Sarmago or Anna Miranda to quote but a few), the greater the care which has to be taken. However, there is little doubt that the more research is involved, the more satisfying the task becomes...

The greatest difficulties I have encountered in crossing the cultural frontiers of languages was dealing with the thin line between what is regional language and what is simply exotic or word play, especially when it is based on sound patterns or onomatopoeia. There is also the important role which the music of the word plays in some works, as in the writings of José Saramago or Milan Kundera. While it may be said that, ultimately, it is possible to translate words directly, cultures, on the other hand, can not be translated directly, without grotesque distortions. 
While Pontiero fears a 'grotesque distortion' of cultures in translation, Ramanujan suggests four things, may be even four articles of faith, which can help the translator in overcoming this problem. These are as Ramanujan puts it with explanatory notes on each, "Universals, Interiorized contexts, systematicity and structural mimicry". I would like here to quote the explanation given by Ramanujan with regard to the 'Interiorized contexts', as he argues that a Tamil poem creates an inter-textual web and that every word is rooted to a specific culture and it can, in association and collocation with other words create a second language which is the poem itself. ${ }^{16}$ I am not sure, if the kind of solution that Ramanujan offers in explaining the 'Interiorized contexts' can be meaningfully accepted by the translator's when the language one translates from is not Tamil. Ramanujan observes:

However culture-specific the details of a poem are, poems like the ones I have been discussing interiorize the entire culture. Indeed, we know about the culture of the ancient Tamils only through a careful study of these poems. Later colophons commentaries explore and explicate this and knowledge carried by the poems, setting them in context, using them to make lexicons and charting the fauna and flora of landscapes... When one translates a classical Tamil poem, one is translating also this kind of inter - textual web, the meaning making web of colophons and commentaries that surround and contextualize the poem. Even when we disagree with them, they give us the terms in which we disagree with them. There is no illusion here of 'the poem itself'.

Neither Pontiero nor Ramanujan nor I believe that no translator can ever present a formulaic solution to the problematic area of culture in translation. A certain strategy to overcome the problem in a particular text cannot or may not necessarily hold good to another text. Moreover, spatiality and temporality also matter 
much in the context of culture, which a translator must bear in mind when translating a particular text. There's possibly no solution; there are only hints and suggestions about the reiteration of the problem. A translator, therefore, has to be flexible, dynamic flanked by his/her ability to comprehend the rich nuances of SL culture and TL culture, so that by understanding and interpreting one, he/she can have the competence to create a context of transfer and then transfer the culture-specific items to the TL text. How to create this contextualization is dependent entirely on the translator's competence in making right kind of choices in order to achieve artistic excellence. Paul St-Pierre highlights the problems that culture unleashes to translation as such and suggests some ways out:

The dilemma faced by translators then is the following: obliged by the differences between languages and cultures to make choices as to how to render them, translators are unable to justify the choices they make purely in terms of the text they are translating. The text forces them into the uncomfortable position of having to intervene and choose, whereas the motivation and justification for the choices made come from elsewhere, not from the text but from the society and culture in which translators are immersed.

This is precisely why I am inclined to credit the translator with creativity - even if it is limited.

\section{The Context of Creativity:}

A translator's creativity stems his/her ability to create a new text in another language. His/her creativity allows him/her to do away with the existing structure - in case of a poem; it can be its stanzaic form. If the translator is unaware of the contemporary reading habits, and translates a $15^{\text {th }}$ or $16^{\text {th }}$ century poem into English in the $21^{\text {st }}$ century, in the manner or style of the SL poem, he/she would be risking the translation. When free verse is in the 
vogue of contemporary taste, by transplanting the SL text's structure or form, which has become either obsolete or hackneyed in the TL context, the translation would appear genuine. Even by free verse translation, one can create a new kind of order, a new kind of movement, a new kind of musicality. This would be a more meaningful exercise than otherwise. In my own translation of Salabega, Bhakta Charan Das, Surya Baladeva Rath, I have digressed from retaining the formal structures of the Oriya poems. If rhymes came automatically in the linguistic flux, I retained them. Similarly, once I tried to translate a few Oriya sonnets into English. I could not keep the line length within fourteen, nor could I maintain Petrachan or Shakespearean model. I had to abandon the idea of translating those sonnets. It would be interesting to make a mention of Tagore's translation, because it evidences his creativity. Tagore was never proud of his English or English rendering of his poems. In a letter to William Rothenstein, he wrote:

I am not such a fool as to claim an exorbitant price for my English which is a borrowed acquisition coming late in my life. I am sure you remember with what reluctant hesitation I gave up to your hand my manuscript Gitanjali, feeling sure that my English was of that amorphous kind for whose syntax a school boy can be reprimanded.

Bikash Chakraborty in a seminal study shows Tagore's intentions behind translating his own poems:

To begin with, the question of fidelity to the original text is perhaps the least aspect of Tagore translation, although the other half of the condition that is, the translated text must look like a text in the target language- was certainly a part of his intention. The question of 'enslavement' to the source text, therefore, does not arise in case of Tagore's translation. 
Tagore's experience as a translator of his own poems was described in a long letter written by Tagore himself to Ajit Kumar Chakravarty on March 13, 1913. Tagore wrote about his creative role as a translator:

... What I like best is when I do my own poems into English. I find the task gripping to the point of intoxication. In the act of translating into an alien language, I seem to find a new flavour in what I had written originally in Bengali. It is almost like a bride's reception at her husband's home- after the wedding is over. By that time the two have already been united in holy wedlock. But the bride must meet and must make friends with the community to which she must belong henceforth. Only after the assembled guests partake joyfully of the feast from the bride's hand, her union with the husband receives the society's sanction. When I wrote originally in Bengali, it was merely a poet's wedding with his muse. Or, in other words, I did not have any clearly defined objective before me other than my poetry. Now that I have got down to translating my poetry into English, it is like sending forth an invitation to everyone to partake of the feast from my bride's hands.

Therefore, the flavour of this joy is somewhat different from what it was before.... The fact is, one cannot really and truly render one's thoughts into another language.... What I try to capture in my English translation is the heart and core of my original Bengali. That is bound to make for a fairly wide deviation. If I were not there to help you out, you must probably find it impossible to identify the original in translation. That, to my mind, is only natural. In her Bengali grab, my muse has to make her appearance bedecked with all her finery and splendour that the resources of the language can command.... But, suppose, that she has to voyage to a far away land on 
her honeymoon; unless she discards the major part of her ornaments and jewellery, these may well prove a burdensome encumbrance. Or suppose she was to go out on a pilgrimage. In that case, she must travel light and not trundle her trousseau about...

I have, therefore, assigned myself the task of disadorning my Muse. The traditional symbols of her marital status- the Vermilion mark at the parting of her hair and the simple iron baangle-are still there. Nor has she been converted into a be-gowned memsahib... How can a Bengali bride cast off her bridal veil! Only the surfeit of ornaments has been drastically cut down to give her a new look of simplicity. Therefore, when my English readers shake their heads in violent protest and claim that this transformation cannot be construed as mere translation. I cannot lightly dismiss what they say. Translated, my Muse could at best find accommodation in some wayside inn or her sojourn abroad... But no, she has been made warmly into their homes, not as a visiting stranger but like a friend and a relation.

They have read something in her face which they see only in the face of a blood relation. They refuse to regard her as an outsider: 'she is our own, our kith and kin,' they say.

As my task of translation is oriented towards this aim, I derive a creative joy afresh out of this exercise. (Italics mine)

What startling paradigm shift in terms of the attitude, stance and practice of a translator and that of the poet as a translator of his own poems! A new set of metaphors could be traced from Tagore's enthusiastic letter. That the translated text for the poet-translator is a "bride"; and this bride can offer a 'feast' to the 'community' to be accepted finally as the legitimate 'wife' of the author. Tagore 
possibly was mistaken to suggest that the bride got warm welcome into the community's home, not as a visiting stranger but like a friend and relation. Tagore's euphoria ended soon, as his letters written to Amiya Chakravarty and Thomas Sturge Moore reveal. Tagore wrote to Amiya Chakravarty on December the 21st 1934:

Glancing through the pieces I found how carelessly I had once translated them. I feel ashamed today that I did not give time enough to notice the extent to which the originals were divested to their intrinsic value in the process of transference to another language.

In another letter written to Amiya Chakravarty on January 06, 1935, Tagore honestly expresses his views against translation, as it is deceptive and admits that he is ashamed of his own translation:

You know when a cow stops giving milk after the death of the calf, a new straw - stuffed shape with the hide of the calf is made so that with the appearance and the smell of it milk trickles out. Translation similarly is the shape of a dead calf which deceives and does not invite. I regret it and am ashamed of it.

To Thomas Sturge Moore, Tagore wrote on 11 June 1935, reiterating this metaphor of deception in another way:

Translation can ... only transfigure dancing into acrobatic tricks, in most cases playing treason against the majesty of the original ... As for myself I ought never to have intruded into your realms of glory with my offerings hastily giving them a foreign shine and certain assumed gestures familiar to you.

Nabanita Dev Sen aptly sums up Tagore's position, in the Western literary scene, even after the Nobel Prize: 
Rabindranath only became a temporary craze, but never a serious literary figure in the Western scene. He was intrinsically an outsider to the contemporary literary tradition of the West, and after a short, misunderstood visit to the heart of the West, he again became an outsider.

Salman Rushdie in his The New Yorker article observes:

Of India's non-English-language authors, perhaps only the name of the 1913 Nobel Prize - winning Bengali writer Rabindranath Tagore would be recognized internationally, and even his work, though still popular in Latin America, is now pretty much a closed book in the United States

Despite the bride's (I mean the translated version of Gitanjali) 'honeymooning' trip or 'pilgrimage' abroad, Tagore remains a Bengali poet as is Pablo Neruda, a poet from Chile or José Saramago a novelist from Portugal. Bikash Chakravarty rightly observes:

But it is more interesting to see that Tagore's translations, often distantly related to the source, are governed more by consideration of ideas than by a principle of form and imagery. In other words, bilingualism in the case of Tagore did not mean that he could write either in English or in Bengali as he chose. He remained a Bengali poet all through his life. When he decided to translate into English he did so because he wanted to put across on a metropolitan plane.

The 'choice' of the poet has to be respected, whether he intended to put across his ideas on a metropolitan plane or universal plane. Our non-acceptance of the translated Gitanjali - and the ideas in it would amount to a great loss in multiple ways hardly to be compensated. When a poet translated his own poems, he/she looks at 
it from one angle, one perspective - i.e. how to re-present the 'core' of the poems in another language. When a translator does it, he/she takes into consideration many aspects of the poems, of the SL culture and TL culture. Pontiero's piece of advice cannot be brushed away:

My own view is that the good translator should be as sensitive as any writer without trying to impose his or her own style.

In Tagore's case, or for that matter in any poet/writertranslator's case, the poet/writer dominates over the poet / writer translator and hence the lack of desired objectivity leading to the metaphor of the surrogate inanimate calf.

\section{Issues unresolved as yet:}

The enormity of the complexities involved in translation as shown by Theodore Savory long ago in his The Art of Translation (1957) remains even undiluted today as we do not have a clear cut choice in the list of choices mentioned by Savory:

- A translation should render the words of ray have additions and deletions.

There can not be any either or situation in adhering strictly to one answer, because no translation is final. Every translation bears a tendency to be appropriated by a time-scale. I am disposed to accept that translation is a progression from exposition towards expansion. Any translation, I am inclined to assert at the end of this paper, locates a context and recreates that context, without failing to allude to the location of the translator. 


\section{REFERENCES}

Walter Benjamin The Task of the Translator, in Illuminations.

(Trans.) Harry Zohn. Glasgow: William Collins: 76.

Henrik Gottlieb (1999) Typologies of Translation, H. Gottlieb. Copenhagen (Ed.), An Introduction to Translation Studies. U of Copenhagen Press .

A.K. Ramanujan (2004) Afterword, Molly Daniels Ramanujan (Ed), Poems of Love and War. Reprinted in Oxford India Ramanujan, Delhi OUP.

Giovanni Pontiero Pillar Orero and Juan C. Sager, (Eds) (1997) The Translator's Dialogue Amsterdam and Philadelhia. John Benjamins Publishing Company.

William Weaver, Biguenet, J. and R. Schulte (Eds), (1989) The Process of Translation, John Benjamins Publishing Company.

Frances R. Aparicio (1991), Versions, Interpretacions Y Creaciones, Gaithersburg, Maryland, Ediciones Hispamerica..

Juri Lotman and B.A. Uspensky (1978) On the Semiotic Mechanism of Culture, New Literary History IX (2).

Susan Bassenett - McGuire (1991) Translation Studies (Revised edition) London and New York : Routledge.

Niranjan Mohanty, Cay Dollerup and Annette Lindergaard (Eds), (1994) Translation: A Symbiosis of Cultures, Teaching 
Translation and Interpreting 2. Amsterdam and New York: John Benjamins Publishing Company.

----- (1921)The Manchester Guardian. Nov 15.

Salman Rushdie (1997) Damme, This is the Oriental Scene for You!, The New Yorker, June $23 \& 30$.

Giovanni Pontiero, Pilar Orero and Juan C Sager, (Eds), (1997) The Task of the Literary Translator, The Translators Dialogue, John Benjamins Publishing Company, Amsterdam and Philadelphia.

Paul St-Pierre (1999) Cake for 'Bread': A Metaphor for Translation, Lipi. Vol. II No. 1 : 92.

William Rothenstein, Collected from Archives, Rabindra Bhavana, VisvaBharati, Santiniketan, India.

Bikash Chakravarty (1997-98) Tagore and the Meaning of Translation, The Jadavpur Journal of Comparative Literature.

------ (1971) The Jadavpur Journal of Comparative Literature, (Trans.) Khitish Roy, Vol. 9.

Collected from the Archives of Rabindra Bhavana, Visva-Bharati Santiniketan. (Trans.) by Bikash Chakravarty.

Cited and translated by Shyamal Kumar Sarkar in Tagore on Translation, The Visva - Bharati Quarterly, Vol. 43 Nos. 1 $\& 2$.

Collected from the Archives of Rabindra Bhavana, Visva - Bharati, Santiniketan. 
Nabanita Dev Sen (1985) Counterpoints: Essays in Comparative Literature, Calcutta: Prajna: 49.

Salman Rushdie (1997) Damme, This is the Oriental Scene for you!, The New Yorker June $23 \& 30$.

Bikash Chakravarty (1997) Tagore and the Meaning of Translation The Jadavpur Journal of Comparative Literature - 98.

Giovanni Pontierro, The Task of the Literary Translator, The Translator's Dialogue.

Theodre Savory (1957) The Art of Translation, London: Cape. 
